\title{
ESTADO ACTUAL Y PERSPECTIVAS DE LA DOMÓTICA
}

\author{
(THE CURRENT SITUATION AND PREDICTABLE FUTURE OF INTELLIGENT HOUSES)
}

\author{
Alfonso Recuero, Dr. Ingeniero de Caminos \\ Instituto de Ciencias de la Construcción Eduardo Torroja (CSIC)
}

ESPAÑA

Fecha de recepción: 27-XII-98

\section{RESUMEN}

Una vivienda domótica es aquélla que, a través de la tecnología, permite "una mayor calidad de vida, una reducción del trabajo doméstico, un aumento del bienestar y la seguridad de sus habitantes, y una racionalización de los distintos consumos; en ella existen agrupaciones automatizadas de equipos, normalmente asociadas por funciones, que tienen la capacidad de comunicarse interactivamente entre ellas a través de un "bus doméstico multimedia que las integra". Para ello, la Domótica prevé la ejecución de ciertas funciones, dependiendo de la información captada por sistemas de medida y trasmitidas a través de redes de comunicación de acuerdo con ciertos estándares. En este trabajo se revisa cuál es la situación actual de estos aspectos y cuál es su evolución previsible.

\section{SUMMARY}

An Intelligent House is the one that allows " a better quality of living through technology, a reduction of domestic tasks, an increase of the well-being and safety of dwellers, and a rationalization of the different consumers power; it includes automatized groups of equipments, usually associated by functions, which have the capacity of interactively communicate between them through an "integrated multimedia domestic bus". For this purpose, the Intelligent House foresees the execution of certain functions, depending on the information captured by measuring systems and sent through the communication network according to specific standards. This paper presents an overview of the present situation regarding these aspects, and their foreseen evolution.

\section{INTRODUCCIÓN}

El término "Domótica" tiene una génesis análoga a la del término "Informática", sustituyendo el prefijo que significa información por otro derivado de la palabra latina "domus", que significa casa. También reciben un trato análogo en la bibliografia en lengua inglesa, en la que son más comunes otros términos como "computing" en lugar de "informática" o los de "smart house" o "intelligent building" en lugar de "Domótica".

La Domótica tiene como objetivo ofrecer una mejor calidad de vida en el lugar habitual de residencia o trabajo, dando respuesta a necesidades tales como:

- Disponer de una temperatura interior confortable en todas las estaciones del año, mediante dispositivos regulables de climatización, teniendo en cuenta el ahorro de energía.
-Disponer de una iluminación suficiente, no deslumbrante, bien repartida según las zonas de actividad.

-Estar protegido de las perturbaciones acústicas, tanto interiores como exteriores, manteniendo un cierto contacto sonoro con el exterior, para evitar la sensación de opresión que genera el aislamiento total.

-Mantener el aire puro, ni muy húmedo ni muy seco, sin corrientes de aire apreciables, a pesar de las actividades domésticas interiores, que aportan distintos grados de humedad y polución.

-Estar protegido frente a las intrusiones de manera que se garantice la seguridad de bienes y personas.

-Asegurar las múltiples tareas domésticas:- limpieza y conservación de los locales, almacenamiento y cocinado de los alimentos, etc. 
-Asegurar las necesidades corporales: comer, dormir, lavarse, mantener la forma.

\section{-Distraerse.}

-Comunicarse, tanto con el interior como con el exterior de la casa.

-Gestionar el conjunto, es decir: aprovisionarse de las materias y de los fluidos necesarios; asegurar el mantenimiento de los aparatos domésticos y optimizar los gastos.

-Trabajary estudiar.

Las necesidades se agrupan en tres grandes familias:

-Necesidades de seguridad, que están relacionadas con la calidad del aire, la prevención de accidentes corporales y materiales, la asistencia a la salud y la seguridad antiintrusión.

-Necesidades de confort ambiental, que implican la creación de un medio ambiente agradable: el confort higrotérmico, el confort acústico, el confort visual, el confort olfativo y el confort espacial.

-Necesidades de confort de actividad, que provienen del deseo de facilitar las actividades cotidianas: dormir, alimentarse, cuidarse, mantener (los locales y los materiales), comunicarse, divertirse, trabajar y desplazarse.

Para cubrir estas necesidades, la Domótica prevé la ejecución de ciertas funciones, dependiendo de la información captada por sistemas de medida y trasmitidas a través de redes de comunicación de acuerdo con ciertos estándares. Vamos a revisar cuál es la situación actual de estos aspectos y cuál es su evolución previsible.

\section{FUNCIONES}

Las funciones de la Domótica se pueden clasificar en: de control, de gestión y de comunicación (Figura 1). Las de control, comprenden: control técnico, seguridad, teletransmisión y asistencia a la salud. Las de gestión, comprenden la gestión de la iluminación, de la calefacción, ventilación y aire acondicionado, de la calidad del aire y de la funcíonalidad de los espacios. Las de comunicación, comprenden: comunicación-control, comunicación-esparcimiento y comunicación-servicios.

La ejecución de una función sigue el siguiente proceso

-Un conjunto de elementos llamados sensores perciben los factores que estimulan nuestros sentidos: vista, olfato, oído, etc., a menudo con un rango más amplio de valores, acrecentando sus capacidades y aportando nuevas posibilidades.

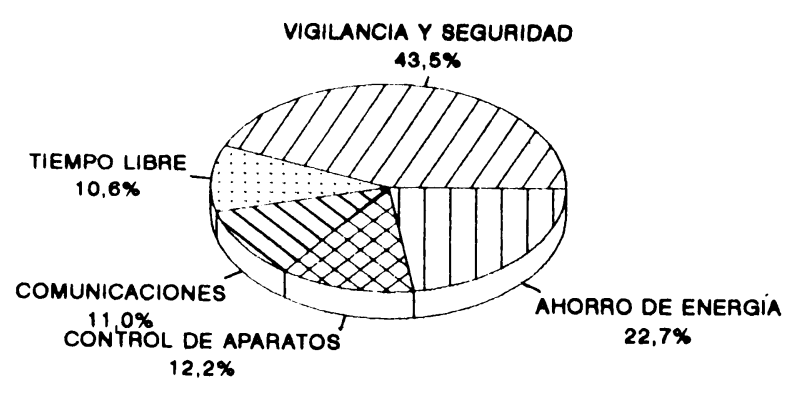

Figura 1.- Funciones requeridas para una vivienda domótica en Italia.

-Estas informaciones son transmitidas a un órgano centralizador, capaz de analizarlas mediante una red de transmisión de señales eléctricas, ya sea por cables conductores, por infrarrojos, por ultrasonidos o por radiofrecuencia.

-Una "inteligencia" (centralizada o descentralizada) capaz de decodificar las señales recibidas de los sensores, de confrontarlas con otros datos y, teniendo en cuenta los programas existentes en su memoria, decide las acciones a ejecutar.

-Las órdenes bajo la forma de señales eléctricas, son transmitidas a los órganos de comando, llamados actuadores, que permiten accionar un interruptor o comunicar un mensaje.

-Además, el autocontrol y la autoprotección del sistema domótico debe asegurar su propia seguridad de funcionamiento.

\subsection{Función de control - comando}

El aumento de dispositivos técnicos en la casa no debe resultar un agobio para el usuario, sino por el contrario, la posibilidad de reagrupar todos los productos en torno a una unidad de tratamiento que permita controlar o prevenir desperfectos, ordenar las intervenciones de mantenimiento preventivo, detectar las anomalías aleatorias gracias a los programas de comparación de parámetros técnicos y teletransmitir a los organismos adecuados para que puedan intervenir rápidamente. La función de control brinda al usuario, por una parte, las informaciones sobre el estado de funcionamiento del inmueble y de las instalaciones que lo integran y, por otra, crean un registro de los distintos parámetros y, eventualmente, inducen comandos correctivos. Para ello se cuenta con controles instantáneos y memorizados e históricos. Las funciones de control asociadas con un algoritmo o con una unidad de tratamiento de la información, conducirán a las funciones de comando, que tiene por objeto actuar sobre los dispositivos de regulación de las instalaciones.

La función control-comando integra las sub-funciones de: control técnico, seguridad y teletransmisión y asistenciasalud.

http://informesdelaconstruccion.revistas.csic.es 


\subsubsection{Control técnico}

La sub-función de control técnico tiene por objeto hacer más confiable el uso de los equipamientos, dispositivos e instalaciones y lograr un mantenimiento predictivo. Por lo tanto, esta sub-función controlará los equipos y electrodomésticos, las redes de suministro y de transmisión de información, los diferentes fluidos utilizados en una casa, las presencias anormales debidas a intrusiones, los parámetros fundamentales -o excepcionales- para verificar el estado de salud de los miembros de una familia, etc.

Los sistemas existentes en el mercado tienen ya algunos elementos de esta sub-función. A pesar de la demora en la definición de estándares, (especialmente en el caso europeo, ya que Japón y Estados Unidos tienen estándares nacionales), los fabricantes han desarrollado algunos dispositivos de vigilancia de calefacción, de presencia anormal de agua y gas, de anomalías en las redes eléctricas. Estos dispositivos son capaces de proteger sus propias redes de distribución-transmisión de la información y ciertos parámetros en los electrodomésticos.

Algunos ejemplos de control técnico son:

-Recepción de mensajes de mal funcionamiento de equipos e instalaciones.

-Centralización del estado de los sistemas de la vivienda como, por ejemplo, puertas o persianas abiertas, luces encendidas, neveras mal cerradas, etc.

-Desconexión selectiva de cargas eléctricas, cuando la demanda de energía eléctrica es superior a la potencia contratada.

-Información de consumos, tarifas y costos de agua, gas, electricidad.

-Dar un conjunto de órdenes de una sola vez para situaciones concretas, por ejemplo, al salir de la casa la última persona $\mathrm{o}$ al irse de vacaciones.

En cuanto a los controles para la higiene y la salud corporal, el mercado es aún muy pequeño y exclusivo, debiendo evolucionar hacia la simplificación y generalización de los sensores confiables, volviendo más accesibles los controles de salud rutinarios. Como ejemplo podemos citar un dispositivo que se usa en el sifón del inodoro que cuenta con un equipo de diagnóstico que, además de medir el pulso y la presión arterial, indica también el nivel de azúcar y de albúmina en la orina, mostrando y registrando todos los datos.

Esta sub-función continuará evolucionando siguiendo los desarrollos de la electrónica y los sensores, para asegurar al usuario un conocimiento preciso de todos sus equipos, instalaciones y de su propio estado de salud, donde la tendencia actual de disminución de los costos favorecerá la creación de un mercado masivo.

\subsubsection{Seguridad y teletransmisión}

En esta sub-función está considerada la seguridad de bienes y personas en relación a los riesgos exteriores o domésticos, voluntarios e involuntarios. Abarca la protección, detección de intrusos en el hábitat, con acción activa o disuasiva; las acciones de seguridad frente a riesgos domésticos (incendio, fugas de agua y gas, riesgos eléctricos, etc.), que comprenden, por una parte, las detecciones y transmisiones automáticas y, por otra parte, implican las acciones de salvaguarda, de reposición del funcionamiento, etc. Por último, dentro de esta sub-función se debe considerar a la tele-vigilancia y la teleasistencia, que abarcan la monitorización de personas de riesgo. Se dispone también de las llamadas "alarmas de salud"-pulsadores distribuidos por la casa o portátiles-, dispositivos que activados por la persona cuando se siente mal, envían un aviso a una central receptora, a un centro sanitario, a un familiar o a un vecino.

La tele-asistencia para personas mayores o discapacitados está aún en los comienzos. Tanto en esta sub-función, como en la de seguridad anti-intrusión parece residir uno de los más importantes mercados del futuro.

\subsubsection{Asistencia-salud}

Existe un desarrollo considerable de esta subfunción en EEUU y en Japón, siendo un área prácticamente sin desarrollar en casi toda Europa. Normalmente consiste en la conexión del usuario a través de un ordenador con centros asistenciales, que aseguran el control y seguimiento de la evolución de ciertos parámetros claves, según cada paciente. El mercado aún no es importante, debiéndose unir a la tele-asistencia para lograr un mayor alcance, si bien todavía falta mucho por desarrollar y avanzar en esta subfunción que algunos la consideran de lujo, pero que, según los casos, puede resolver inconvenientes reales de algunos sectores de la población, tales como discapacitados (transitorios y permanentes), personas de edad, etc.

\subsection{Función de gestión}

La función de gestión tiene por objetivo automatizar un cierto número de acciones, principalmente relacionadas con el confort. Las automatizaciones se realizan según una programación, un control de los consumos y un mantenimiento predictivo. A continuación, se describen brevemente cuatro sub-funciones: gestión de iluminación; gestión de calefacción, aire acondicionado y ventilación; gestión de la calidad del aire y funcionalidad de los espacios. 


\subsubsection{Iluminación}

Esta sub-función ofrece como servicio medir y asistir al usuario en la gestión de uno de los primeros elementos ligados al confort, en los distintos ambientes del hábitat. Debe adecuarse a las necesidades de cada uno según edades, capacidades físico-motrices, uso de los espacios a lo largo del día, ciclo diurno/nocturno, empleo del tiempo, repercusión sobre la ocupación de los espacios, etc. Otro aspecto que debe abarcar es la optimización del uso y de los gastos de electricidad, sin menoscabo del confort de los usuarios, aportando servicios complementarios por la temporización, la variación de intensidad o el encendido/apagado automático, programado o controlado a distancia.

La gestión de la iluminación puede estar facilitada de diversas maneras:

-Gestión globaldezonas mediante comandos programables, según los protocolos de los sistemas, los modos de vida, etc.

-Encendido/apagado de zonas, voluntaria o aleatoriamente, en caso de entradas/salidas o de ausencias.

-Temporización de la iluminación en zonas de uso intermitente (pasillos, garajes, baños, etc.), utilizando sensores infrarrojos, pasivos o activos, que detectan movimiento $o$ presencia.

-Comando por radiofrecuencia, permitiendo desde el exterior o cualquier lugar de la casa la gestión de un espacio elegido, el apagado de las luces de noche, la iluminación externa, etc.

-Variación de la intensídad de la iluminación, por radiocomando, desde el sistema central o directamente por el usuario en forma manual.

Estas acciones pueden ser realizadas desde el interior de la vivienda por el usuario mediante la interfase correspondiente o ser conectadas desde el exterior vía telefónica, por radiocomandos, etc. Cada acción puede ponerse en marcha automáticamente, ser cancelada desde el interior o el exterior o ser ejecutada en forma manual. La utilización de los radiocomandos en iluminación no es lo más usual, pero en el caso de personas temporalmente privadas de autonomía o discapacitados, resulta de interés, ya que permite la integración de la gestión de iluminación con la de funcionalidad de los espacios, a través de un único telecomando.

\subsubsection{Calefacción, ventilación, aire acondicionado}

Desde un comienzo, la Domótica buscó, principalmente, que el usuario pudiera medir y controlar su calefacción,

(c) Consejo Superior de Investigaciones Científicas

Licencia Creative Commons 3.0 España (by-nc) así como las cargas energéticas y su propio confort. La necesidad de controlar las cargas en los inmuebles de vivienda colectiva y repartir individualmente los gastos del consumo por calefacción, ha favorecido la introducción de nuevos conceptos, que luego fueron adoptados para la vivienda individual.

Los nuevos sistemas domóticos ofrecen servicios según requerimientos de uso, que se complementan, permitiendo al usuario:

-Activarlos a distancia.

-Pasar automáticamente de un régimen "confort" a un régimen reducido, cuando no hay personas en la vivienda.

-Desactivar la calefacción o el aire acondicíonado de una habitación, si la ventana está abierta.

-Optimizar el ambiente de cada habitación, poner en funcionamiento el cierre parcial de cortinas o persianas exteriores, etc.

-Regular la temperatura habitación por habitación.

Los sistemas más evolucionados son auto-adaptativos, teniendo en cuenta el medio ambiente, que reconocen en un corto tiempo de aprendizaje. Otras mejoras que se pueden prever son aquéllas relacionadas con un mejor control y mantenimiento de los equipos; esto depende de otra función (control técnico y autodiagnóstico) y puede generar diferencias notables en los consumos.

\subsubsection{Calidad del aire}

Desde hace algunos años se viene manifestando un interés general por la preservación del medio ambiente y, en particular, por la calidad del aire, en las grandes ciudades. Cada vez más, se realizan mediciones de la calidad del aire, controlando la presencia y la cantidad de ciertos elementos implícitamente peligrosos u olfativamente indeseables.

Pocos sistemas domóticos tienen en cuenta la gestión del aire. Algunos abordan solamente el problema de la higrometría del aire, si bien los ensayos más simples de calefacción por aire tratan únicamente el aspecto térmico, dejando a los dispositivos anexos la necesidad de regular independientemente este parámetro. Se puede realizar, con sensores ya existentes y confiables, la gestión de la temperatura-humedad, para mantenerse siempre en la zona de confort.

En el caso de otros medios de calefacción, la cuestión es más simple, ya que la extracción de aire húmedo puede ser independiente del sistema de regulación de temperatura y tratado habitación por habitación. No obstante, pocos 
sistemas comercializados integran la gestión de la higrometría del aire.

En cuanto a los gases contaminantes, la Domótica ha considerado al metano proveniente de las fugas de gas como primer elemento a ser controlado. Es importante, por lo que implica desde el punto de vista de la seguridad individual y colectiva, que las fugas de gas sean detectadas y controladas y que la acción sea inmediata (cierre de válvula, transmisión de una alarma, etc.). Ya se han empezado a encarar acciones de control para otros tipos de gases. Se prevé que las investigaciones y desarrollos realizados para la industria agro-alimentaria serán transferidos al hábitat, pero no parece que esto sea de forma inmediata.

Por último, la gestión de calidad del aire, en sentido amplio, queda como un área a explorar y desarrollar en los próximos años, debiéndose analizar la factibilidad técnica y económica de su aplicación al hábitat.

\subsubsection{Funcionalidad de los espacios}

Ésta es una necesidad que nace de la evolución de los espacios según las modificaciones de los grupos familiares, las adaptaciones a las nuevas necesidades, los nuevos modos de vida, etc. Para la Domótica la flexibilidad de los espacios, las instalaciones y los equipos es de vital importancia, debiendo considerar qué condiciones habrá de reunir un edificio y con qué elementos técnicos deberá estar equipado, para estar a la altura de las exigencias del presente y del futuro.

Dicho de otra forma, un edificio domótico debe proyectarse de manera que la variabilidad esté ya prevista en el proyecto. Por lo tanto, es necesario garantizar la adaptabilidad en el futuro, mediante un proyecto y un equipamiento adecuado. Debe tenerse en cuenta la estructura del edificio, fachadas flexibles e interactivas, la construcción flexible de pisos y techos, etc.

El edificio deberá ser un conjunto flexible que integre distintas tecnologías, en el que pueden coexistir sistemas de gestión, sistemas de control energético, sistemas de vigilancia y mantenimiento, sistemas de seguridad, sistemas de comunicación interna y externa, así como también sistemas mecánicos, eléctricos y electrónicos. Estos sistemas también deberán poder conectarse entre sí.

\subsection{Función comunicación}

La tendencia mundial, tanto en electrónica de consumo como en telecomunicaciones, es hacia la interconectividad, teniendo en cuenta las funciones requeridas en el ambiente doméstico y servicios disponibles vía las redes de telecomunicaciones. Los servicios y aplicaciones de las comunicaciones contemplan el intercambio de mensajes, tanto entre personas, como entre personas y equipos, dentro de la propia vivienda y de ésta con el exterior. La función comunicación será analizada a través de tres subfunciones, que son: comunicación-control, comunicación-esparcimiento y comunicación-servicios.

\subsubsection{Comunicación-control}

En la década de los setenta se asistió a la utilización de redes de telecomunicaciones parcialmente superpuestas, físicamente solapadas, aunque funcionalmente separadas, de acuerdo con las velocidades de difusión o con la innovación de cada momento y de cada nuevo concepto tecnológico. La opción tecnológica era entonces doble: o permitir la proliferación de redes de soporte a tantos servicios como el mercado demandase o racionalizar el espectro disponible, aprovechando el uso generalizado de las técnicas digitales en el procesamiento de la información involucrada en cada aplicación o servicio. Esta segunda alternativa es la que tecnológica y económicamente se impuso, generando entonces el concepto de Red Digital de Servicios Integrados (DDSI). Es decir, una red única que, asentada en una técnica común de procesamiento digital de la información, soporta, de manera integrada, todos los servicios de voz, texto, datos e imágenes (fijas o móviles de baja definición).

Como ya fuera planteado en las funciones de control y gestión, la importancia de la Domótica reside en la posibilidad de que todos los dispositivos y equipos de la vivienda estén comunicados entre sí y, a su vez, con el hombre.

La introducción de las diferentes técnicas digitales y de los microprocesadores en el control de gestión de los diferentes dispositivos y terminales de servicios domésticos, con su reducción en última instancia a un lenguaje binario de comandos, que también es compartido por las señales correspondientes de audio, texto, datos e imágenes, genera nuevas potencialidades.

En primer lugar, las técnicas de control y operación son similares y comunes a todos los dispositivos. En segundo lugar, se puede distanciar el operador (ya sea una persona $\mathrm{u}$ otro dispositivo inteligente de control) del dispositivo en sí. Éste es el caso de los telecomandos. Finalmente -y esto es un salto cualitativo- si, hasta ahora, cada dispositivo se comunicaba sólo con el operador humano o con el controlador inteligente (nunca más de un dispositivo conectado a un único operador), a partir de las técnicas de control y señales digitales, idénticas en su naturaleza, los distintos dispositivos pueden comunicarse entre sí, ya sea para intercambiar señales de vídeo, sonido, audio, etc.

\subsubsection{Comunicacion-esparcimiento \\ El espacio de ocio se encuentra enriquecido por los}


servicios de otras funciones por intermedio de periféricos, de telecomandos infrarrojos y de protocolos de comunicación con funcionalidades crecientes. La concentración en un mismo telecomando para el conjunto de los aparatos habitualmente utilizados supondría ya un "plus" en relación a la multiplicidad de controles remotos a la cual se asiste actualmente -hecho que responde a una falta de normalización entre aparatos-. Las facilidades de gestión aportadas por la concentración en un telecomando único y la posibilidad de utilizarlo a partir de múltiples receptores de aparatos, generan un mayor confort.

El servicio a ofrecer por la sub-función de comunicaciónesparcimiento es: llegar a concentrar en un punto los aparatos de base de audio y de vídeo-comunicación; hacerlos comunicar entre ellos para resolver los problemas de telecomandos múltiples; y crear en las otras habitaciones los receptores de comando conectados en una misma red/ bus de comunicación.

Por último, debemos mencionar el salto cualitativo que constituye la Red Digital de Servicios integrados de Banda Ancha, así como también al Compact Disc Interactivo (CD-I) y el DVD. Este último, es, probablemente, el paradigma de esta revolución de las técnicas de control y las facultades ampliadas de almacenamiento y reproducción de imágenes (fijas y móviles) y de sonido. .

\subsubsection{Comunicación-servicios}

Para ciertas informaciones y servicios, es necesario conectarse con el exterior. La red interna debe, por lo tanto, estar unida a una red exterior pública y/o privada. El acceso al mundo exterior se logra a través de distintas interfases. La responsabilidad de la interfase es unir el sistema domótico con el mundo exterior.

La sub-función de comunicación-servicios es propia de una sociedad moderna, a la cual la Domótica y otras tecnologías interactivas favorecen en su desarrollo y expansión. Los servicios que se están perfilando como los más prometedores en el sector residencial son: el teletrabajo, la tele-educación, el tele-mantenimiento, la televigilancia-asistencia, los tele-servicios, etc.

\section{SISTEMAS DE MEDICIÓN}

La posibilidad de adaptar un edificio según los cambios del medio se basa en el uso de sistemas que permitan medir dichos cambios. Para satisfacer las necesidades de seguridad, confort ambiental y confort de actividad necesitamos contar con informaciones que deberían estar fácilmente disponibles desde cualquier lugar de la vivienda.

Un sistema de medición, en general, consta de cuatro tipos de elementos: el sensor, el acondicionador de señal, el procesador de señal y el de presentación de los datos.
El elemento sensor, que está en contacto directo con la magnitud físico-química a medir, da una salida proporcional a dicha variable. Por ejemplo: para termopares, la salida en milivoltios depende de la temperatura; para bandas extensométricas ("strain gauges"), la resistencia depende de la deformación mecánica. Si hay más de un elemento sensor en un sistema, al elemento en contacto con el medio se le considera sensor primario; a los otros, sensores secundarios. Los sensores aplicados en la Domótica son, generalmente, multifuncionales no pueden ser asociados con un campo particular de aplicación. Los detectores de movimiento, por ejemplo, son de particular relevancia en todo el manejo del edificio: energía, seguridad y confort. Detectan la presencia de movimiento como la expresión más obvia de vida, que es el criterio que controla la mayoría de los servicios de la vivienda.

El elemento acondicionador de señal toma la salida del sensor y la convierte en la forma más adecuada para procesarla posteriormente, generalmente en señales de tensión continua, corriente continua o frecuencia. Por ejemplo: un puente de Wheatstone convierte variaciones de impedancia en cambios de tensión.

El elemento procesador de señal toma la salida acondicionada y la convierte a una forma conveniente para la presentación. Por ejemplo: un conversor analógico a digital convierte la tensión a una forma digital adecuada para ser procesada por una computadora.

El elemento de presentación de datos presenta el valor medido en una forma que puede ser fácilmente reconocida por el observador. Ejemplos de esto: un display alfanumérico, un plotter.

El término transductor es generalmente usado en conexión con medición e instrumentación. Es un dispositivo que traduce a salida eléctrica variables de entrada físicas o químicas. Un transductor incorpora el sensor y el acondicionador de señal. Un ejemplo: una celda de carga convierte deformación -por presencia de un peso- a variación de resistencia. Los transmisores captan la variable física $o$ química a través del elemento sensor y transmiten a distancia la señal de salida normalizada.

Los sensores se pueden clasificar en pasivos y activos. Los primeros necesitan tensión de alimentación externa para dar una señal de salida, ya sea en tensión, corriente o frecuencia, como, por ejemplo, los sensores resistivos, capacitivos, inductivos. En cambio, los sensores activos son dispositivos que autogeneran tensión y no necesitan fuente de alimentación externa. Ejemplo de estos sensores son: diodos fotovoltaicos, termopares, cerámicos piezoeléctricos, que producen señales de tensión relacionadas con entradas no eléctricas. Los sensores resistivos, capacitivos e inductivos, son la base fundamental para la medición de un conjunto de variables físicas esenciales en la Domótica.

http://informesdelaconstruccion.revistas.csic.es 


\section{REDES DE COMUNICACIÓN}

Una red es un conjunto de conexiones entre un cierto número de elementos de un sistema (Figura 2). Una red de comunicación permite a los elementos de un sistema comunicarse entre ellos. La comunicación entre dispositivos o equipamientos compartidos se hace por medio de redes locales, que posibilitan la interconexión de una variedad de dispositivos de comunicación de datos (ordenadores, terminales, periféricos, sensores, teléfonos, fax, etc.) dentro de un área, usualmente con extensiones de hasta $10 \mathrm{~km}$. Las informaciones transferidas por una red de comunicación, en forma de mensajes, consisten en bits, organizados en caracteres, estructura de datos, etc. Los mensajes son unidades lógicas de transferencia de información entre tareas que controlan un dispositivo particular o que ejecutan una función específica tal como un algoritmo de control, adquisición de datos, etc. Los mensajes transmitidos por la red de comunicación pueden ser caracterizados por el tiempo de respuesta, por la rapidez con que los mensajes son transferidos, por la cantidad de información a ser transferida y por la fiabilidad o la importancia de una transferencia libre de errores.

Uno de los más importantes beneficios de una red local es la posibilidad de evolución del sistema, ya que es posible una modificación gradual evitando y simplificando traba- jos complejos. Además, permite la conexión de dispositivos de varios fabricantes, lo que proporciona al usuario mayor flexibilidad y autonomía.

La red domótica o, en otros términos, el cableado es el que permite realizar una comunicación entre los diferentes aparatos conectados a la red y es el instrumento esencial sobre el que se basa la Domótica. Las redes destinadas a los edificios inteligentes dependen de las aplicaciones y en ellos se utiliza, a menudo, una red separada e independiente para cada función. Así, hay redes dedicadas a la seguridad, a la detección de incendios, al control de accesos, a la climatización, a la informática, etc.

Las redes domóticas son, en términos generales, redes polivalentes que permiten realizar diferentes funciones a fin de simplificar la complejidad y la instalación de la red. La misma red asegura, por ejemplo, las funciones de seguridad, confort y gestión técnica. La red puede estar constituida por uno o varios soportes de comunicación de acuerdo a las funciones a realizar por el sistema domótico.

En cuanto a las topologías de redes, existen dos clases básicas de redes locales: punto a punto "store and forward" y multipunto "broad cast". La primera es de arquitectura simple, con unión bidireccional: un bloque completo de información es recibido por un nodo o estación interme-

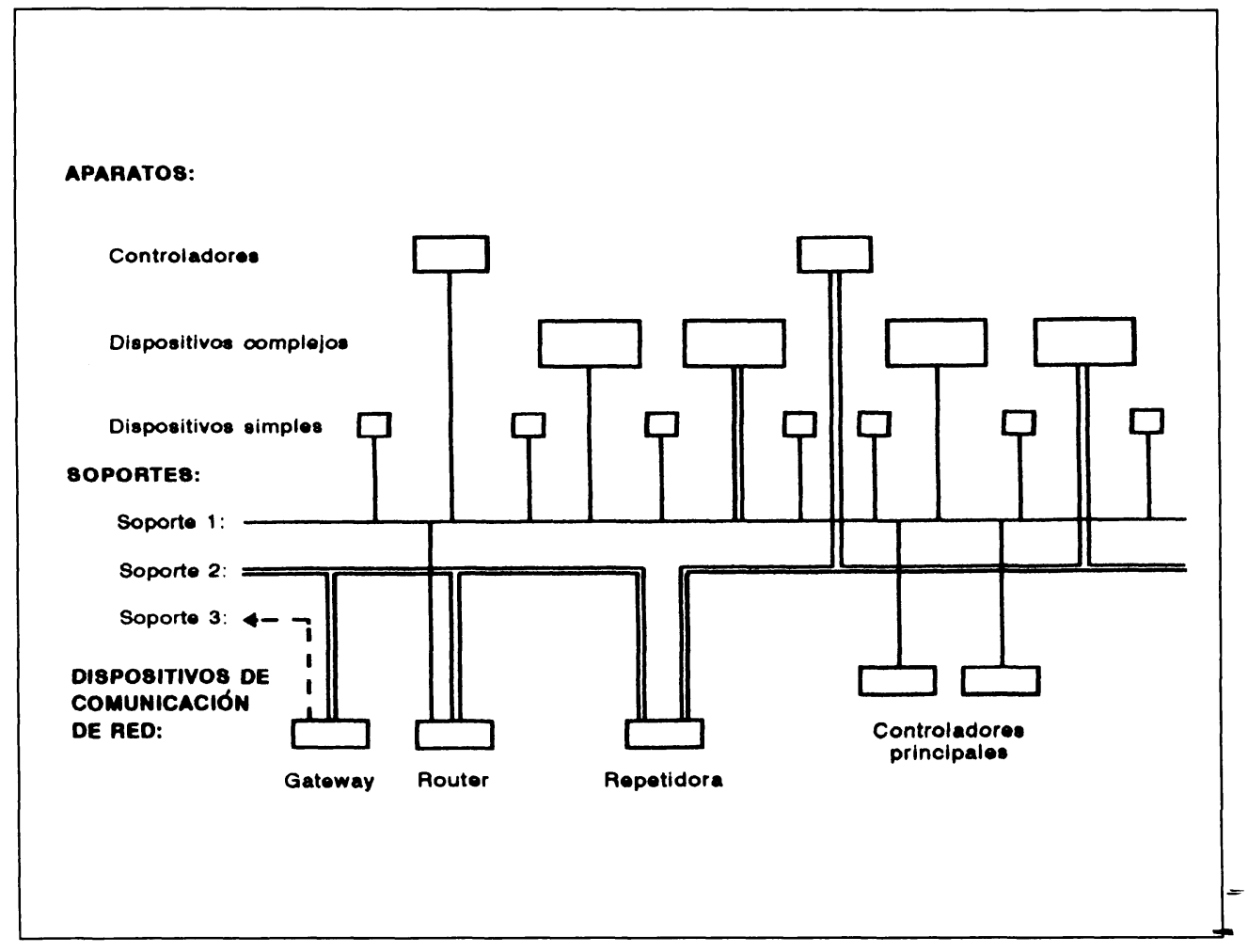

Figura 2.- Ejemplo de una red domótica. 
dia antes de ser retransmitido a su destino final. En una red multipunto, un mensaje transmitido por un nodo es recibido por todos los nodos que están conectados a un medio de transmisión común.

El término nodo o estación representa una unidad compuesta por uno o más procesadores que ejecutan una o más tareas relacionadas con la aplicación, incluyendo las funciones de comunicación. En general, los nodos son conectados por uniones, punto a punto, independientes.

La topología de una red está definida por el modo en que los nodos están interconectados, de lo que depende su fiabilidad y la posible reconfiguración. No existe una topología única que sea apropiada para todas las aplicaciones. Las topologías básicas son (Figura 3):

-En estrella, en la que todos los aparatos están conectados separadamente a un nodo central. Las diferentes estrellas pueden constituir las extremidades de otra estrella (estrella de estrella o árbol). Se pueden distinguir dos variantes: estrella activa, en la que existe un nodo central que asegura las funciones. Esta red es simple, confiable y económica, pero poco flexible, las uniones son bidireccionales; y estrella pasiva, en la que el nodo central actúa como un nodo más y no tiene valor agregado.

-En BUS (Binary Unit System), en la que todos los aparatos están conectados al soporte de comunicación que recorre el conjunto del sistema. Existen dos variantes: bus direccionaly doble bus unidireccional, o bus bidireccional.
-En anillo, en la que todos los aparatos están conectados en serie en un circuito cerrado. Las informaciones son transmitidas, de un aparato al otro, en forma unidireccional. En la red anillo puede existir un controlador de lazo.

Es necesario hacer una distinción entre la arquitectura física (la disposición real de los cableados en el edificio) y la arquitectura lógica de una red (de acuerdo con la forma en que los aparatos están conectados entre sí). Así, una red precableada, por ejemplo, con topología en estrella, que es la más utilizada (arquitectura física), permitirá posteriormente, a partir de un nodo central, interconectar los aparatos de acuerdo a la topología más conveniente, sea ésta estrella, bus o anillo (arquitectura lógica).

Teniendo en cuenta las funciones a realizar, la red hará uso de uno o varios soportes de comunicación. Si bien las características técnicas de los diversos tipos de soportes de comunicación son muy distintos, todos ellos deben permitir la transmisión de mensajes numéricos, que permiten la comunicación entre los diferentes aparatos de una red. Algunos soportes son capaces de transportar señales en tiempo real, tales como las señales de audio (vozy música) y las señales de vídeo (antena, cámara, etc.) Ciertos soportes pueden, además, alimentar los aparatos conectados con corriente continua o alterna, como, por ejemplo, electrodomésticos, termostatos, etc.

Los tipos de cableados o soportes de una Red pueden ser línea eléctrica (Powerline), en par trenzado (Twisted Pair), Coaxil, Fibra Óptica, Infrarrojo y Radio-frecuencia.

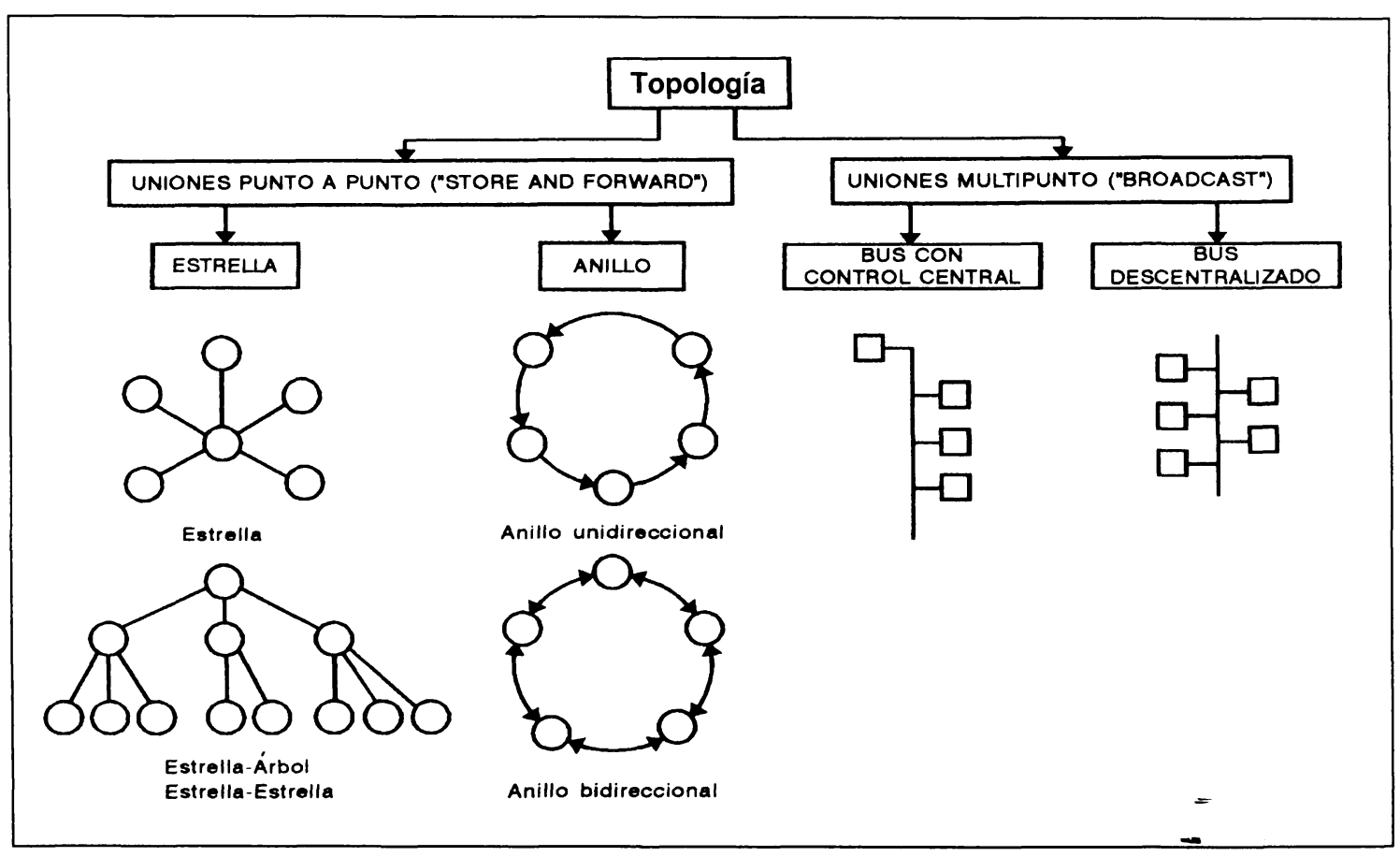

Figura 3.- Topologias de redes. 
Para que los aparatos de diferentes fabricantes puedan funcionar sobre una misma red, es necesaria una estandarización en el netware domótico, ya que los diferentes sistemas actualmente en el mercado son poco o nada compatibles. El principio por el cual pueden comunicarse entre ellos es el llamado principio de sistema abierto y está basado en el modelo OSI-MODEL (Open System Interconnection).

Los métodos de acceso que se pueden utilizar para transmitir mensajes son:

-Acceso aleatorio. Un aparato conectado puede, en todo momento, enviar un mensaje sin preguntarse si la red está libre.

-El aparato prueba primero como está la red y, si está libre, envía el mensaje, con o sin escucha durante la emisión para detectar las colisiones.

-Acceso "TOKEN" El "Token" o "permiso de emitir" es transmitido de un aparato a otro: el aparato que desea enviar un mensaje pone el token en "ocupado" y agrega su mensaje; El destinatario recibe el mensaje, da una confirmación al token y lo reenvía al expedidor; éste constata que su mensaje ha sido recibido, pone el token en "libre" y lo transmite al aparato siguiente.

El establecimiento de una comunicación entre dos subredes del mismo o de distinto tipo puede hacerse mediante: un "repeater" que une sub-redes de la misma naturaleza, que pueden ser consideradas como una misma red; un "bridge" o "router", responsable de direccionar los intercambios de datos entre dos redes; o un "gateway", que por llevar "traductor" incorporado, puede unir, entre ellas, dos redes de tipo totalmente diferente.

\section{ESTÁNDARES}

La Domótica es también un campo de competencia técnico-comercial de proveedores de bienes y servicios específicos. De ahí las dificultades para acordar una normalización técnica común, pues se entiende que quien logre forzar la adopción de todo o parte de un estándar determinado está imponiéndose a la competencia, o simplemente a otros sectores de actividad económica, que tendrán costes adicionales para la adecuación a la norma impuesta. La estandarización es condición necesaria, aunque no suficiente, para poder abrirse realmente paso en el mercado, lograr series continuas de productos, disminuir costos, estabilizar criterios tecnológicos, generar confianza en los usuarios, etc.

Un estándar no es otra cosa que las normas que impone un comité formado específicamente para examinar, evaluary seleccionar la mejor de las recomendaciones aportadas por las diferentes empresas, compañías o instituciones

(c) Consejo Superior de Investigaciones Científicas

Licencia Creative Commons 3.0 España (by-nc) gubernamentales. La estandarización del medio físico y de los protocolos de acceso y comunicación es clave por varias razones, entre ellas: independizar el cableado interior del tipo de dispositivos que se utilizarán, asegurar la interconectividad de dispositivos de distintos tipos y proveedores y permitir la transportabilidad de terminales y dispositivos.

Los dispositivos requieren de energía y están conectados a una red fisica de información interna, integrada total o parcialmente a las redes de energía externa, por medio de interfaces específicas para la conexión con las redes públicas de electricidad, agua, gas, etc., o la conexión a las redes públicas de telecomunicaciones y la recepción de señales de difusión de vídeo, datos y sonido, sean terrestres o vía satélite.

En la década de los ' 80 , las comisiones de estandarización domótica comenzaron a trabajar con dos enfoques sustancialmente diferentes: por un lado, las redes de servicios de telecomunicaciones, tendían a mirar al espacio cotidiano como una prolongación de sus propias redes; por otro, los constructores de edificios y proveedores de dispositivos para el hogar, tendían a ver a éste como un contexto con identidad propia, lo cual implicaba un tratamiento diferencial, usando las redes externas como una simple conexión enriquecedora. En 1987, la EIA de Japón aceptó el primer estándar de bus doméstico, mientras que en Estados Unidos, los estándares se van decantando rápidamente, habiendo sido incorporado uno de ellos por la National Electrical Code. Esta circunstancia ha presionado sobre Europa, donde el tema fue encarado como iniciativa comunitaria, a través de proyectos tales como EUREKA, IHS (Integrated Home System), ESPRIT II (Home Systems Project) etc. Veamos los estándares más utilizados.

El sistema X-10 representa el estándar de control de la línea eléctrica. Consta básicamente de un controlador (transmisor) y un interruptor remoto (receptor). Los controladores X-10 envían señales digitalmente codificadas a los módulos de recepción a través del cableado existente.

El interruptor remoto puede ser conectado a cualquier toma eléctrica. Un electrodoméstico queda conectado a un receptor, que comprueba continuamente la llegada de señales codificadas a través de la línea eléctrica, que son recibidas e interpretadas por la electrónica situada en el receptor.

Las señales X-10 se basan en detección de pasos por cero que determinan las señales codificadas. Hay dos tipos de señales: el código de dirección y el código de función. Así, el sistema X-10 permite al usuario contrelar manualmente cualquier aparato conectado a un interruptor remoto al presionar un botón, que corresponde a un receptor particular.

http://informesdelaconstruccion.revistas.csic.es 
El sistema no tiene inteligencia para ejecutar tareas de modo automático. En el caso que se desee incrementar su capacidad es necesario integrar al sistema X-10 un microprocesador.

La ventaja es que no se requiere cables adicionales y el existente puede ser usado para estos propósitos; sin embargo, no es un medio ideal para la comunicación debido al ruido, fluctuaciones e interferencias.

Un consorcio de empresas fundado por la NAHB, The National Association of Home Builders, ha desarrollado un nuevo sistema de control y distribución eléctrica integrado para viviendas unifamiliares, llamado Smart House (Figura 4).

El sistema incluye diseños avanzados de distribución de gas, cableado eléctrico y componentes electrónicos, que trabajan en forma conjunta para lograr una automatización integrada, reemplazando el cableado convencional por una familia de tres cables, que llevan potencia, teléfono, vídeo y señales de control a toda la casa. Estos cables son:

-Un cable híbrido que distribuye la potencia y los mensajes de control por toda la casa.

-Un cable de comunicación que distribuye señales de audio, vídeo y teléfono y que contiene dos cables coaxiles, cuatro pares trenzados y fibras ópticas opcionales. Los cables coaxiles son usados para la distribución de audiovídeo y transmisión de datos de alta velocidad.
-Un cable de aplicación, que distribuye señales de control para productos de baja tensión, como, por ejemplo, detectores de humo o sensores, controladores de panel, etc.

La infraestructura del sistema Smart House consta, básicamente, de un "centro de servicios", un sistema de cableado y las salidas. El centro de servicios es el lugar donde todos los suministros externos entran al hogar. La función de dicho centro es la de controlar y distribuir estos suministros vía los cables a los equipos.

La inteligencia del Smart House reside en el controlador, que tiene dos funciones principales: el manejo de la red y el manejo de las aplicaciones.

Pueden utilizarse distintos sistemas de comunicación.

El PL es, probablemente, el más importante de todos los medios de comunicación. Esto se debe a que la mayoría de los productos a ser controlados están conectados a la línea eléctrica.

El TPBuses, normalmente usado para baja potencia, termostatos, sensores de seguridad, teléfonos, etc. utiliza cuatro pares de conductores: un canal de datos/control combinado y los otros pares son canales de datos. En el IRBus la velocidad de transmisión es de $10 \mathrm{kbits}$ con una frecuencia portadora en el rango de $70 \mathrm{a} 80 \mathrm{kHz}$. El RFBus trabaja en la banda de $902 \mathrm{MHz}$ y el CXBus es normalmente usado para transmisión de datos.

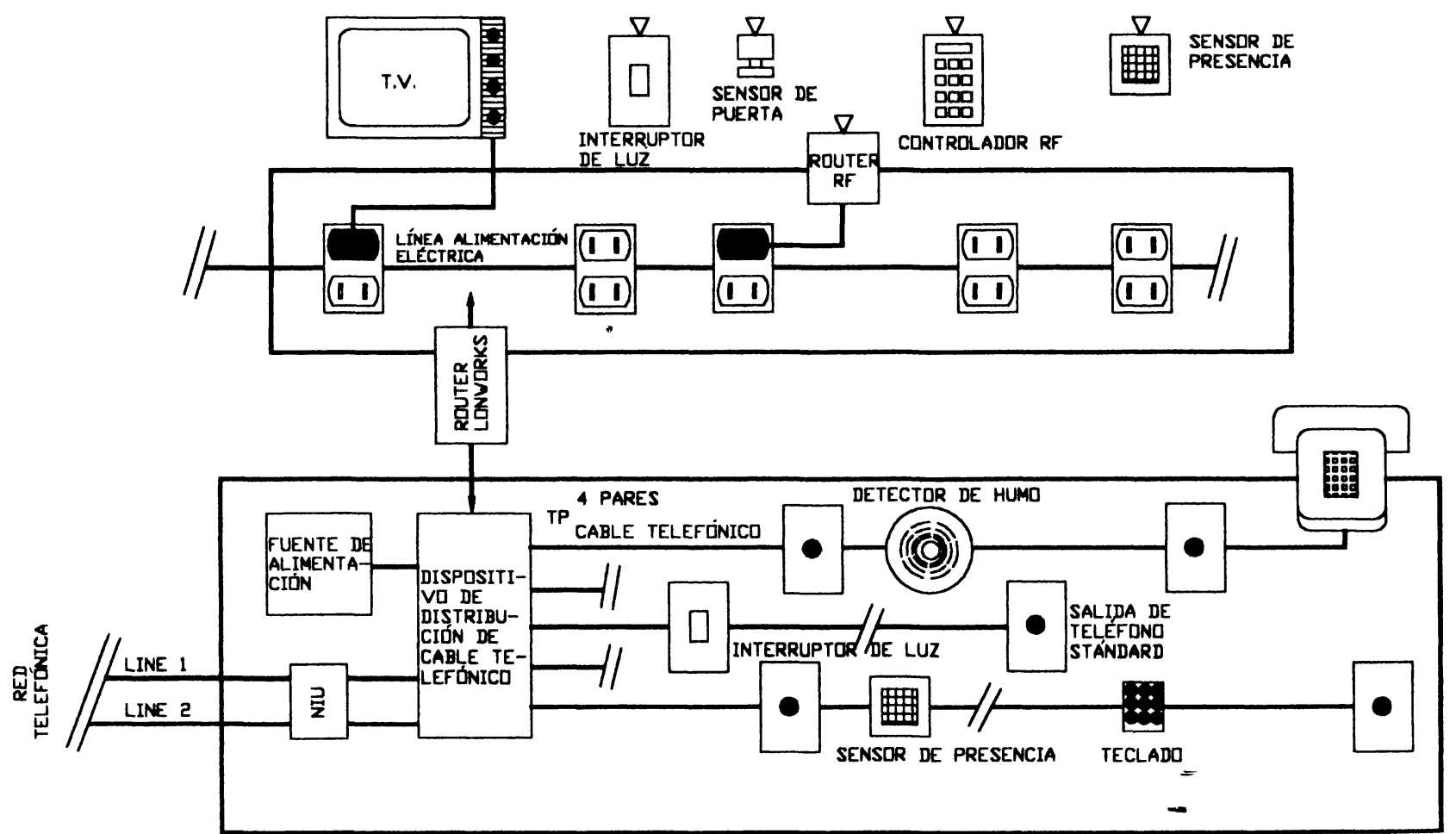

Figura 4.- Topología de control de Smart House. 
CEBus (Consumer Electronics Bus) está diseñado para el mercado residencial norteamericano. Sobre un medio CEBus se puede transmitir simultáneamente dos tipos de información: de control y de datos. Así, el CEBus usa un canal de control para transmitir información de control (encendido, apagado, aumento y disminución de volumen, etc.); el espectro de frecuencia usado para la transmisión varía para cada medio de comunicación. Los canales de datos se usan para transmitir información de no control (voz, datos, vídeo, texto, gráficos, etc.).

Local Operating Networkers (LON) fue desarrollado por Echelon Corporation. Su concepto es similar al Smart House CEBus, el cual permite la comunicación entre productos, colocando un chip multifunción en cada producto (electrodomésticos, aparatos de iluminación, interruptores, etc.). Un LON está diseñado para llevar mensajes cortos de control, estado y datos. Cada LON cuenta con dispositivos llamados nodos. Un nodo consta de: hardware de aplicación, un chip "neurona" que provee el protocolo de comunicación y software de aplicación, y un transmisor/receptor que provee una conexión a un medio de comunicación específico.

ElESPRIT HS (Esprit Home Systems), tiene por objetivos definir las especificaciones técnicas de un sistema electrónico de comunicación y de información, asegurando la compatibilidad y la interoperatividad de equipamientos y aparatos en edificios del sector residencial y del sector terciario, precisar y mostrar la interoperabilidad de las diferentes aplicaciones en los edificios y estudiar los sistemas de distribución de la energía eléctrica en lo que concierne a los aspectos de seguridad de funcionamiento y de utilización e integración de los sistemas de comunicación. La arquitectura del sistema de comunicación ESPRIT-HS está basada en la utilización de soportes de transmisión múltiples.

DDB (Domestic Digital Bus) fue desarrollado por Philips y aprobado por ISOIIEC, como una norma de comunicación para sub-sistemas de entretenimiento (vídeo y audio) del hogar. Philips y Matsushita formaron, recientemente, "una jointventure" para promover el D28. Otras empresas como, por ejemplo, Sony y Thomson están involucradas en este sistema. Actualmente se están desarrollando los gateways para conectar el D2B al Smart House, CEBus, ESPRITHS.

HBS (Home Bus System) HBS, fue desarrollado por fabricantes japoneses para el hogar japonés. Usa una arquitectura de control centralizada. Los buses de comunicación principales son el cable coaxil y el par trenzado. El HBS provee salidas de comunicación con el exterior similares a las de electricidad y teléfono que permitirán a los usuarios obtener información interna y externa.

HES (Home Electronic Systems). HES se basa en el OSI; pero debido a que los requerimientos del HES son más específicos que los de este último y también por razones de eficiencia de protocolo, algunas de las capas del modelo de referencia OSI, se redujeron o anularon funcionalmente en el modelo HES.

El comité de la Organización de Estandarización Internacional (ISO) y la Comisión Electrotécnica Internacional (IEC) están trabajando en la normalización internacional para el HES. Su objetivo es especificar una interfase y un lenguaje de comando que permita a los productos del hogar operar con cualquier red de comunicación domótica.

\section{LÓGICADIFUSA}

La lógica difusa es una técnica de cálculo que promete mejorar el control de sistemas difíciles de modelar. En la teoría de conjuntos clásicos un elemento pertenece o no pertenece a un conjunto, y una aserción es cierta o falsa. Sin embargo, en lógica difusa un elemento puede pertenecer parcialmemte a uno o varios conjuntos (expresando su grado de pertenencia por un valor entre 0 y 1). Esto permite su uso en sistemas poco conocidos, no lineales o imprecisos. Esta teoría fue introducida por Jan Lukasiewicz en los años 30, ampliada por Max Black y ampliamente desarrollada por Lotfi A. Zadeh.

Cuanto más complejo es un sistema, más difícil es conocerlo en sus detalles. Esta teoría trata de describir estos sistemas lingüísticamente en lugar de matemáticamente, cuando este modelo no existe, es complicado de codificar o difícil de evaluar en tiempo real, y cuando una o más de las variables de control son continuas. Esto permite introducir reglas heurísticas y de buena práctica, o la experiencia, proporcionando sistemas robustos, tal como se ha mostrado en diversas aplicaciones. Pueden citarse supervisores de temperatura que satisfacen a la mayoría de los ocupantes de un edificio, minimizando los costes de operación compensando las variaciones de uno a otro día.

Normalmente, junto a las variables numéricas ordinarias, se toman una o varias funciones de control (temperatura, humedad relativa, ruido ambiente, luminosidad, etc.) y se denomina error de las mismas a su diferencia con los valores óptimos. Puede estudiarse este error y también su variación. En función de estos parámetros pueden activarse las reglas lingüísticas que expresan la experiencia para el control del sistema.

\section{DEMOSTRADORES}

Las primeras experiencias de viviendas domóticas comenzaron en la década de los ' 80 y en los últimos años el número de prototipos demostradores se ha multiplicado, de tal forma, que hoy resultaría casi imposible hacer un listado completo de los mismos. Entre los primeros pueden mencionarse los siguientes. 
La SociedadOSAKA GAS, -segundo distribuidor de gas en el Japón-, decidió, en 1982, hacer un prototipo (concluido en 1985) de casa del futuro, al que llamó "CASA JEXT", prevista para albergar una familia representativa de los hogares japoneses, integrada por tres generaciones: una pareja con dos hijos y dos mayores. Su concepción inicial era anticiparse al estilo de vida de los años ' 90 , haciendo uso del gas como fuente principal de energía; incluía: la utilización racional de la energía, a través de equipos de gas económicos y de baterias solares; la automatización de la gestión, del control-comando y de la información; receptores para videotexto, videodisco, bandas de datos, televisión por cable y por satélite; la salud y la seguridad de los residentes.

Elproyectopiloto TRON(The Real-Time Operating System Nucleus), fue promovido por 18 empresas japonesas e inaugurado en diciembre de 1989. La casa, situada en el centro de Tokio, tiene una superficie de $230 \mathrm{~m}^{2}$, y fue diseñada para un matrimonio con un hijo y una habitación a la "japonesa" para los mayores. Se planteó como objetivo de esta construcción ofrecer, mediante una completa información de todos los sistemas y componentes del edificio, el máximo estándar de confort, comodidad y seguridad para las personas que lo habitaran. El edificio piloto de vivienda individual cuenta con una instalación de más de 400 microprocesadores, con los que se gestiona una amplia gama de elementos constructivos e instalaciones técnicas especiales.

-El enfoque americano, a través del proyecto Smart House es radicalmente diferente. El objetivo fijado fue ofrecer al usuario servicios innovadores y nuevas funcionalidades replanteando completamente el problema de la distribución de la energía y los medios de comunicación y control. La principal originalidad de este proyecto radica en el cableado. Una red unificada, provista de una inteligencia distribuida, asegura la distribución eléctrica, el control de las comunicaciones audiovisuales, datos, telefonía e interfonía. Todos los aparatos y productos domóticos deben estar conformados a los protocolos de comunica- ción para díalogar con los sistemas de control, los sensores y el sistema central. En 1987 se construyeron dos casas prototipo en Baltimore y, posteriormente, otras quince en otras regiones de EEUU. En 1991 se comenzó la comercialización del SMART HOUSE.

La operación "DORIS" (DO de Domótica y RIS de RISLER, la ciudad francesa donde se realizó esta experiencia), consistió en el reciclaje de un inmueble de 42 viviendas. Las dos funciones, consideradas esenciales en este sistema, son la seguridad y la gestión, incluyendo: seguridad-vigilancia, gestión técnica, mensajes, consumo de calefacción.

La casa Lyon panorama fue instalada en la comuna de Caluire et Cuire, cerca de Lyon y está organizada en dos niveles. El sistema domótico multi-componentes instalado permite asegurar las funciones en tres áreas: la gestión de la energía, la seguridad de bienes y personas y el control-comando de los equipamientos.

-El Proyecto Domos fue promovido por el Instituto Cerdá de Barcelona. Comenzó en junio de 1990 y terminó en diciembre de 1992. El objetivo principal fue elaborar información estratégica, recomendaciones y propuestas operativas, orientadas a la toma de decisiones y puesta en marcha de iniciativas que permitieran el desarrollo y consolidación del mercado de las viviendas inteligentes en España. Se ha llevado a cabo una experiencia piloto incorporando sistemas domóticos a viviendas, con el fin de determinar aspectos tales como: sobrecoste inicial, modificación del proceso constructivo, servicios y aplicaciones comercializables, costes de mantenimiento y grado de satisfacción de los usuarios. Dicha experiencia se ha llevado a cabo en una promoción publica de ocho viviendas y en otra promoción inmobiliaria privada en un bloque de doce viviendas, situadas ambas en la provincia de Barcelona. Más recientemente (1998), se han construido bloques de viviendas de protección oficial en San Sebastián, de entre 70 y $80 \mathrm{~m}^{2}$, con objeto de mostrar que las viviendas domóticas no han de ser necesariamente caras.

\section{BIBLIOGRAFÍA}

(1) TRICIA PARKS: The state of home systems. The computer application journal 25, feb-mar 1992, pp. 12-21.

(2) KENDAVIDSON: The home control system: supervisory controller. The computer application journal, 25 feb-mar 1992, pp. 46-56.

(3) H. BROOKE, STAUFFER: The Smart House system. The computer application journal 31, feb. 1993, pp. 14-23.

(4) PATRICIA M., ANGEL LILIANA y B. FRAIGI: Introducción a la Domótica, TOMO 1. VI Escuela Brasileño - Argentina de Informática, Embalse, Córdoba - Argentina -julio de 1993.

(5) WALTER BANKS, ASHOK PATEN and SHERIF ABDEL-KADER: A home control system based on fuzzi logic. Home automation \& building control,jul. 1995,pp.51-57.

(6) G.S. VIRK, A. B. GHAZALI and D. AZZI: Fuzzy Logic Control of Building Management Systems, UKACCInternational Conference on CONTROL 96, 2-5 september 1996, Conference Publication No. 427, IEE 1996, pp. 180-185. 
(7) CHRIS SAKKAS: An Introduction to Fuzzy Logic, Circuit Cellar ink 75, oct. 1996, pp. 12-27.

(8) JOHN HOKENSON: Wiring your house for the 21-st century, Circuit Cellar project file 2, pp. 35-60.

(9) CONSTANTIN VON ALTROCK: Practical Fuzzy Logic Design, Circuit Cellar ink 75, oct. 1996, pp. 16-20.

(10) CONSTANTIN VON ALTROCK: A Fuzzy Logic Thermostat, Circuit Cellar ink 75, oct. 1996, pp. 22-27.

\section{Publicaciones del Instituto Eduardo Torroja-CSIC}

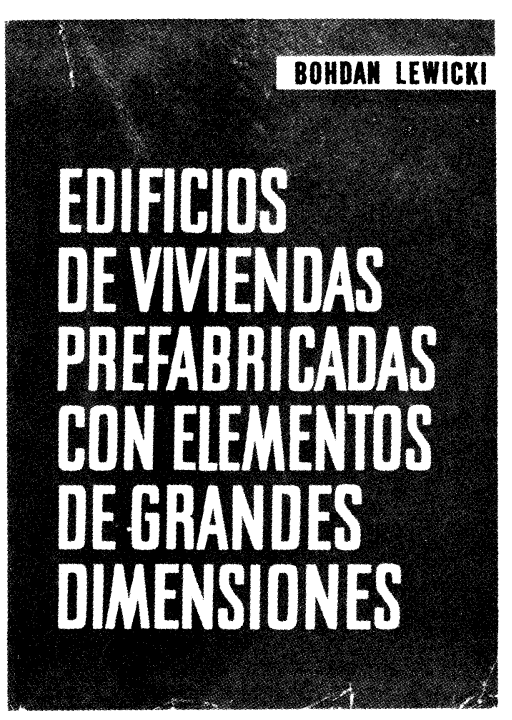

Bohdan Lewicki

Este libro trata de los problemas relativos a la construcción de los edificios de viviendas o publicos realizados con elementos prefabricados de grandes dimensiones. Se han estudiado los problemas de arriostramiento, asi como los que plantea la resistencia de los elementos y de la estructura; se han examinado las cuestiones de orden higrotermico, acústico y de resistencia al fuego: también se ha profundizado en el estudio tambien se ha profundizado en el estudio de las juntas.

La obra incluye numerosas ilustraciones que dan detalles de diversas soluciones, as como ejemplos de cálculo, tablas de valores numéricos, diagramas y ábacos.

Un volumen encuadernado en tela, de $24 \times 17 \mathrm{~cm}$, compuesto de 616 págs.
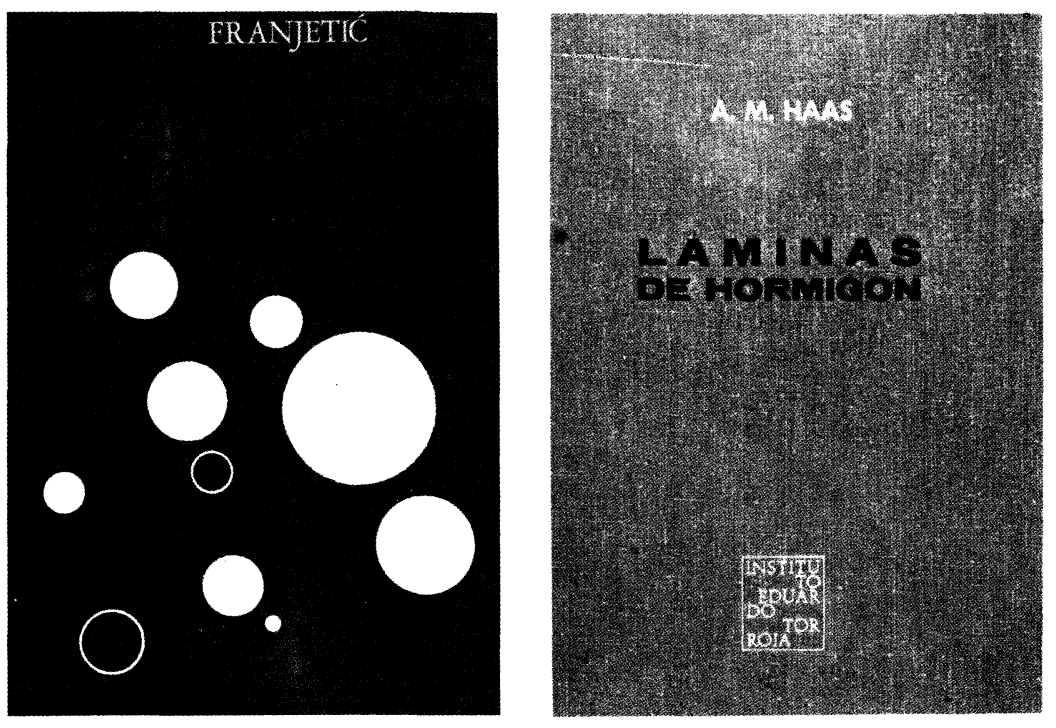

Zorislav Franjetic

\section{A. M. Haas}

En la obra de Franjetic se expone de una forma minuciosa, ordenada y sistemática, todo un cuerpo de doctrina que reúne el conocimiento actual sobre el endurecimiento rápido del hormigón. Parte el autor de los principios básicos y llega a las últimas consecuencias y realidades técnicas y economicas.

Es una obra de consulta, tanto para el investigador sobre la materia, como para el proyectista y el realizador y montador de plantas e instalaciones y equipos de curado y endurecimiento rápido.

Un volumen encuadernado en cartóné, de $17 \times 24,5 \mathrm{~cm}$, compuesto de 385 págs. 110 figuras y 10 tablas.
Al escribir este libro el autor intento poner a disposición de los estudiantes y de los ingenieros unos conocimientos prácticos, adecuados para servir de guia en el diseño y construcción de láminas delgadas de hormigón.

El autor está convencido de que el éxito en el diseño de una lámina exige, por parte del proyectista, un examen de las tres fases por las que pasa la materialización de la lámina: el diseñc, el análisis estructural y la construcción de la estructura.

Un volumen encuadernado en=tela, de $17 \times 24,5 \mathrm{~cm}$, compuesto de 420 págs., 141 figuras, 22 fotografias y 6 tablas." 